\title{
LA PRODUCCIÓN DE TALAVERA DE PUEBLA Y SAN PABLO DEL MONTE, TLAXCALA: UN SISTEMA PRODUCTIVO LOCAL EN TRASFORMACIÓN
}

\author{
Jessica Mariela Tolentino Martínez \\ jestolentino@yahoo.com.mx \\ Facultad de Filosofía y Letras \\ Universidad Nacional Autónoma de México \\ Rocío Rosales Ortega \\ rro@xanum.uam.mx \\ Universidad Autónoma Metropolitana, Iztapalapa \\ México
}

\section{RESUMEN}

Este artículo analiza las diversas etapas de desarrollo de la producción de la talavera, prestando particular atención al conjunto de relaciones sociales que han dado lugar a la formación de un sistema productivo local. Entre los elementos que destacan en el sistema productivo local se encuentran la difusión del conocimiento tácito, la conformación de instituciones reguladoras del proceso económico, así como la construcción de redes sociales y económicas entre productores.

Palabras clave: sistema productivo local, instituciones, redes económicas y sociales.

\section{ABSTRACT}

This paper analyzes the different stages of development that the production of Talavera earthenware has been through. Special attention is placed on the array of social relations that have led to the emergence of a local production system. The dissemination of tacit knowledge, the creation of institutions in charge of regulating the economic process, as well as the construction of social and economic networks among producers are among the elements that stand out most in the local production system.

Key words: local production system, institutions, economic and social networks. 


\section{INTRODUCCIÓN}

El estudio de la producción de la cerámica y en particular de la talavera de Puebla ha recibido mucha atención por parte de historiadores y artistas interesados en rescatar las tradiciones mexicanas. Por ese motivo, la aportación de este trabajo de investigación ${ }^{1}$ consiste en estudiar la producción de la talavera desde una perspectiva geográfico económica, en donde se presta mayor atención al proceso de formación y organización de lo que denominamos un sistema productivo local. Para lograr este objetivo analizamos el papel del conocimiento tácito en la trasferencia de las habilidades y experiencia del oficio entre los productores de la talavera, la formación de instituciones generadas por las asociaciones de productores, así como también a la articulación de redes sociales y económicas que organizan la producción entre los municipios del estado de Puebla y San Pablo del Monte, en Tlaxcala.

En primer lugar presentamos los elementos teórico metodológicos que caracterizan al sistema productivo local y analizamos cada uno de ellos en el contexto de nuestro estudio de caso. En un segundo apartado proporcionamos los antecedentes históricos que permiten hablar de un proceso de coordinación de mercados de la producción de la cerámica, la cual experimenta varias etapas de auge y declive debido a la interrelación de las condiciones internacionales, nacionales y regionales, en la organización de la producción de la talavera en nuestra área de estudio. En un tercer apartado, presentamos las principales características que han definido, a través de la historia, la producción de la talavera en Puebla así como su proceso de difusión en el municipio de San Pablo del Monte, en el estado vecino de Tlaxcala.

En las reflexiones finales realizamos un balance entre los logros obtenidos en el proceso de formación del sistema productivo; tales como la difusión del conocimiento y la formación de un oficio que proporciona oportunidades de trabajo a múltiples artesanos de las localidades aledañas, al mismo tiempo que evaluamos los futuros retos que experimentan los productores. 


\section{EL SISTEMA PRODUCTIVO LOCAL Y SUS DIMENSIONES DE ANÁLISIS}

A partir de la década de los años ochenta, surgió el interés desde diversas disciplinas sociales, por analizar la noción de desarrollo con base en las particularidades del territorio y la contribución a éste por parte de los actores locales. En esta línea de reflexión, el territorio deja de ser visto como un depósito de recursos disponibles para su uso, y comienza a concebirse como un ámbito de construcción de recursos mediante las relaciones que establecen los seres humanos, entre ellos, y con su entorno (Morales 2003). Su análisis se vuelve importante para estudiar la configuración de regiones diferenciadas en torno a actividades económicas y sociales particularmente localizadas. De esta forma, el espacio local va a ser diferenciado no solo por sus recursos naturales, sino también por la capacidad de organización de los sujetos que convergen en él.

De acuerdo con Kuri (2006: 132): «...un sistema productivo es un complejo históricamente constituido y organizado bajo una dinámica económica conjunta...» que favorece la formación de ventajas competitivas mediante el aprovechamiento del conocimiento del contexto local que las pequeñas empresas realizan. Por lo tanto, el sistema productivo local se basa en la reagrupación geográfica de empresas y actores en una misma actividad económica. Por su parte, Klein (2006: 311) considera que la proximidad social y cultural conduce a los actores socioeconómicos a «...adoptar estrategias de gobernanza local con el fin de unificar la acción de los actores productivos y las empresas...». De esta forma, los sistemas productivos se van a diferenciar de acuerdo con sus potencialidades de desarrollo, las cuales dependen de la toma de decisiones de los actores locales. Así, el sistema productivo local es una respuesta a la trasformación productiva, empresarial y organizativa del territorio.

De esta manera, el sistema productivo local se configura como una visión que propone nuevos niveles de análisis y de organización del territorio. En esta propuesta los actores locales, su cultura, identidad y arraigo social, son aspectos importantes que además de contribuir en la calidad de vida de los habitantes, favorecen la productividad y competitividad del espacio local. 
Es decir, el espacio social va a constituirse por el proceso particular de producción y las relaciones socioeconómicas generadas al interior del territorio. Por lo tanto, el sistema productivo local se inserta en un espacio que es reproductor y reproducido por las distintas acciones que llevan a cabo los actores locales en un determinado territorio, lo que conduce a hablar de un espacio socialmente construido.

\section{DIMENSIONES DE ANÁLISIS DEL SISTEMA PRODUCTIVO LOCAL}

El Sistema Productivo Local se nutre de una serie de elementos que permiten crear un ambiente favorable para la organización económica de un grupo social, entre ellos encontramos la aglomeración de un conjunto de MPyM empresas, las instituciones, el capital social y humano, que permiten construir relaciones de confianza y reciprocidad que soportan la organización económica; las redes sociales y económicas que favorecen la articulación de las diversas cadenas de producción y comercialización. A continuación analizamos cada uno de ellos para comprender sus características.

\section{CAPITAL Y REDES SOCIALES, CAPITAL HUMANO Y CONOCIMIENTO TÁCITO}

En las últimas décadas el concepto de capital social ha sido recuperado desde diversas disciplinas para estudiar el carácter social y cultural de las relaciones económicas, aspecto que había sido relegado ante el predominio, de la economía neoclásica. El capital social se define con base en la confianza, la reciprocidad y las redes sociales. Estos conceptos influyen en las expectativas que tienen los individuos en los patrones de interacción de los individuos en una actividad recurrente (Ostrom 2003: 171).

El capital social es definido como el conjunto de recursos derivados de la participación en redes sociales, estos recursos, a su vez, son entendidos como obligaciones de reciprocidad e información (Bourdieu 1997, Bourdieu 1980, Herreros 2002). La reciprocidad se vincula con el establecimiento de la confianza ${ }^{2}$ entre los individuos, con el hecho de no romper normas implícitas o explícitas que han sido aceptadas en la red de la cual forman parte.

El concepto de capital social se analiza a través del concepto de redes sociales, las cuales son definidas como «...uno de los tipos más importantes de estructuras sociales 
en las que las transacciones económicas están imbuidas. Estas son un conjunto de asociaciones recurrentes entre grupos de gente vinculada por lazos ocupacionales, familiares, culturales o afectivos» (Portes, citado por Mora 2004: 48). La familia es la red social básica que se desarrolla con futuras interacciones sociales. Las redes sociales según la intencionalidad que tengan pueden ser de tipo económico, territorial, de innovación, de aprendizaje, pero en su esencia todas son de carácter social porque implican el establecimiento de interacciones entre los individuos. Dichas interacciones pueden ser recurrentes o no, de ahí la fortaleza o debilidad de los lazos establecidos y la posibilidad de creación de capital social.

Si bien las redes sociales fuertes o densas son las que sirven para generar mayor interrelación y por lo tanto beneficios a un grupo social, Granovetter (1973) indica que los vínculos débiles pueden ser en un momento dado más importantes que los vínculos fuertes para la renovación de contactos y apertura de un grupo social ante el mundo. Por tanto, observamos que a la hora de querer iniciar cualquier actividad son tan útiles las redes sociales densas como las débiles ya que permiten reducir la incertidumbre, generar mayores procesos de innovación y disminuir los costos de transacción.

Otro elemento fundamental que se encuentra en estrecha interrelación con el capital social es el capital humano. De acuerdo con Ostrom (2003: 170) el capital humano se forma concientemente mediante la educación y la capacitación que se proporciona por medio de procesos codificados y estandarizados que se organizan de manera formal, mientras que, por otra parte, a través de la experiencia se aprende de manera inconciente, por medio de prácticas sociales informales que dan lugar al conocimiento tácito (Dutrénit 2001: 212). En este sentido, durante su proceso de formación participan procesos de inversión concientes e inconcientes; en donde la adquisición de nuevas capacidades incluirá también el aprendizaje de restricciones. El capital humano es un elemento determinante para llevar a cabo una actividad de forma exitosa, y en este sentido su proceso de formación es un aspecto fundamental en la comprensión de los procesos de aprendizaje que caracterizan la difusión del conocimiento y habilidades en una comunidad de aprendizaje como la que se integra en los sistemas productivos locales. Es importante mencionar que la trasmisión del conocimiento tácito también 
depende, en gran medida, de las redes sociales con las que cuenta el individuo y que le permitirán en determinado momento acceder al capital social mediante la cooperación entre actores.

\section{REDES ECONÓMICAS: CADENAS DE PRODUCCIÓN Y COMERCIALIZACIÓN}

Las redes económicas se constituyen tanto por cadenas de producción como por cadenas de comercialización. Las cadenas de producción se conforman por un conjunto de actores que participan en el proceso de producción, el cual comprende cualquier actividad que sirve para satisfacer necesidades humanas creando mercancías y servicios que se destinan al intercambio (Sabino 1991). Por otra parte, las cadenas de comercialización se integran por un conjunto de intermediarios que intervienen en la comercialización de un bien, desde el productor hasta el consumidor. Según las características físicas y económicas de los bienes éstas puede variar drásticamente. La cadena de comercialización, aunque en apariencia encarece el producto final, es imprescindible para que este llegue oportunamente a los consumidores que lo demandan, constituyendo por lo tanto un elemento indispensable en el funcionamiento de una economía de mercado (Sabino 1991).

Tanto las cadenas de producción como las cadenas de comercialización son los procesos fundamentales de un sistema de producción, sin embargo los aspectos que los diferencian encuentran su explicación en la forma como las redes sociales les imprimen un carácter particular que busca adecuarse a los intereses de los grupos sociales que interactúan en un sistema productivo. En este sentido coincidimos con Semitiel y Noguera (2004) al definir el sistema productivo como el conjunto de relaciones económicas, que incluye relaciones formales e informales entre empresas, actores sociales e instituciones.

\section{LA INNOVACIÓN TERRITORIAL}

Actualmente, en la lógica capitalista, la creación de nuevas tecnologías y la disposición de éstas por los diferentes países han llevado a una mayor competencia entre los distintos territorios. La competitividad de los países se encuentra determinada por la capacidad de desarrollar innovaciones ${ }^{3}$ (Caravaca 1998: 2). 
Tradicionalmente la innovación tecnológica se consideraba una condicionante del crecimiento regional dentro del sistema capitalista, sin embargo, a partir de la década de los noventa se comienza a ver la innovación no necesariamente ligada solo a la tecnología, sino además con la innovación territorial. En la innovación territorial el proceso de aprendizaje individual y colectivo, la organización empresarial y las redes de cooperación entre actores locales, facilitan el crecimiento económico y social, lo que permite dar respuesta a los retos de la globalización (Méndez 1998).

Para Alburquerque (2004) las innovaciones pueden ser de dos tipos: innovaciones tecnológicas, las cuales requieren cambios o mejoras gerenciales y organizativas en el funcionamiento de las empresas e innovaciones sociales, las cuales acompañan a las tecnológicas y las hacen posibles. Las innovaciones sociales son nuevas alternativas y nuevos métodos de gestión de personal tales como la racionalización de las tareas laborales, las mejoras en las condiciones de trabajo, etc. Muchas de las veces, el éxito competitivo no depende tanto de la adquisición de bienes materiales como de las mejoras organizativas y de los cambios sociales y culturales que permiten redes de comunicación capaces de desarrollar sinergias positivas.

Caravaca (2005) ofrece mayores elementos de análisis de la innovación en relación con el territorio, al hablar de la innovación empresarial e innovación social. La primera puede ser cuantificada e identificada de acuerdo con el aumento de las inversiones, la creación de empleos y mejoras significativas de infraestructura. La segunda no es tan fácil de medir dado que tiene que ver con «...la cohesión social, territorial, desarrollo de sinergias, reforzamiento de la identidad local, implicaciones en las instituciones locales en proyectos colectivos, puesta en valor de los bienes patrimoniales, aumento de la equidad y del bienestar social...» (Caravaca 2005: 10). Tanto la innovación empresarial como la innovación social son procesos importantes en la trasformación del espacio local. Por ello, es imposible privilegiar una sobre la otra dado que ambas influyen directamente en el funcionamiento del sistema productivo. 
INSTITUCIONES

Hasta finales de la década de los ochenta se observaba cierta dificultad por parte de la economía para incorporar el papel de los agentes y los gobiernos en el desenvolvimiento de la actividad económica; no es sino hasta la década de los noventa que se observa el interés por parte de la economía institucional y, sobre todo, de parte de la geografía económica institucional por establecer un vínculo entre los agentes económicos y la configuración de las instituciones que caracterizan a los territorios.

En esta lógica, concebimos las instituciones como instancias que promueven y constriñen la conformación de hábitos, rutinas y prácticas sociales que reproducen el conjunto de la vida social, y en donde las actividades económicas son una parte de ella (Nelson y Sampat 2001: 19). Las instituciones son producidas y reproducidas mediante hábitos y rutinas de los sujetos u organizaciones, lo cual permite reproducir, regular y coordinar las acciones sociales, entre ellas el desempeño económico de un lugar en particular (Nelson y Sampat 2001: 34).

De esta forma, mediante la interrelación entre arreglos institucionales - formas particulares de organización, tales como mercados, firmas, sindicatos, asociaciones, etc.- y el ambiente institucional — sistema de prácticas socializadas, costumbres, normas y rutinas sociales - la geografía económica analiza con mayor profundidad las particularidades institucionales de un lugar, en la medida que las interacciones sociales son específicas del mismo (Martin 2000; Rosales 2010). Como producto de la vinculación entre la libertad de acción de los actores y el proceso de formación de las instituciones, los arreglos institucionales no solo reproducen sino también pueden trasformar el ambiente institucional.

\section{EL ORIGEN DE LA TALAVERA EN LA CIUDAD DE PUEBLA Y EN SAN PABLO DEL MONTE TLAXCALA}

La ciudad de Puebla de los Ángeles se caracterizó en su fundación, ${ }^{4}$ por ser el principal centro manufacturero del país en donde se producía tanto textiles como jabón, velas, cristal, porcelana, artículos de alfarería, cuero y hierro (Thomson 2002). Por la ciudad pasaban dos caminos comerciales importantes: uno venía de la ciudad de México a 
Puebla y se dirigía al sureste, al puerto de Veracruz; el otro camino seguía la misma ruta hasta Puebla pero se desviaba hacia el suroeste en dirección hacia Oaxaca y Guatemala. De esta forma, los comerciantes poblanos cubrían el consumo local y regional abasteciendo así dos mercados muy importantes: la capital de México y el puerto de Veracruz (Liehr 1993).

Hoy día, la ciudad de Puebla si bien no es el principal centro manufacturero continúa siendo una entidad económica importante para el país. No solo se puede decir que se han mantenido las actividades manufactureras tradicionales de la región sino que también fueron surgiendo nuevas plantas manufactureras. En particular cuando se habla de Puebla se le asocia con diversos productos artesanales, entre ellos destaca la loza de talavera.

El origen de la talavera en Puebla ha sido uno de los temas de mayor discusión, sobre todo por historiadores del arte, ya que la mayoría de los trabajos de investigación de la región apenas si se detienen a mencionar la actividad. Las publicaciones que se han generado muestran que la loza de talavera es una de las principales industrias artesanales de Puebla, cuyas primeras noticias datan del siglo XVI (Quintana 1971).

En el trabajo de Cervantes (1939, t. II), se menciona que la fabricación de azulejos se inició en Puebla a partir del establecimiento de los primeros alfares entre los años de 1560 a 1580. Huerta (1992) menciona que el nombre de la loza fabricada en Puebla en la época colonial proviene de la población de Talavera de la Reina, en España. Peñafiel (1910) supone que algunos de los primeros pobladores de la ciudad originarios del arzobispado de Toledo fueron los introductores de la talavera. Otros autores mencionan que se le llamó talavera por ser en un inicio una copia fiel a la elaborada en la población Talavera, cuyos productos se imitaron desde principios del siglo XVI en los alfares de Sevilla, Triana y otros lugares de España, los cuales fueron inspiración directa de la cerámica vidriada (Peñafiel 1910, Cervantes 1939, t. 1: X, Pérez y Ovando 1979).

El origen y la denominación de la talavera, como se puede apreciar, no está del todo esclarecido. Sin embargo, se sabe exactamente que la fabricación de dicha loza se 
originó pocos años después de la fundación de Puebla (Cervantes 1939, t. I). La facilidad con la que se reprodujo la loza en la ciudad de Puebla tuvo que ver con la habilidad de los indios de la región, quienes eran artesanos hábiles para la fabricación de la cerámica (Hoffman 1922).

Los maestros loceros que llegaron a la Nueva España se encontraron con arcillas diferentes a las de su país de origen, lo que en un inicio les dificultó la elaboración de loza, motivo por el cual pensaron en traer las arcillas desde Toledo. Sin embargo, no tardaron en darse cuenta que la combinación de dos barros, uno encontrado en el cerro de Loreto de color parduzco, al que llamaron negro, y otro de color rosado que denominaron rojo y que, hasta hoy día, se localiza en grandes cantidades en las cercanías de la jurisdicción de Tecalí (Cervantes 1939 t. I) era la mezcla perfecta para la loza debido a su excelente calidad (Ventosa 1971).

La cercanía con los depósitos de arcilla necesarios para obtener el color y la consistencia ideal fue uno de los aspectos que determinaron el asentamiento de la producción de cerámica de talavera en la ciudad de Puebla (Connors y Contreras 1999). Otro aspecto importante fue la localización estratégica de la entidad que permitía con relativa facilidad la venta y distribución de sus productos hacia las diversas ciudades de la Nueva España. De esta manera, la cerámica continuó adquiriendo tanta importancia que las autoridades eclesiásticas del obispado de Tlaxcala presionaron para que los productos de loza pagaran diezmo, pleito que los loceros ganaron argumentando que las lozas de España no lo pagaban (Castro 1989).

A finales del siglo XVI existían tres locerías y a mediados del siglo XVII estas aumentaron significativamente debido a la aceptación y demanda principalmente de la gente acomodada de la ciudad (Cervantes 1939 t. II). Paulatinamente su empleo se volvió común, de tal forma que prácticamente para el siglo XVII no había construcción en la ciudad que no contara con azulejos en su decoración. Fue tanto el aumento de los establecimientos de locerías y tanta la demanda de aprendices que querían ingresar, que se optó por reglamentar el oficio y formar un gremio con el que se pretendía establecer 
una serie de condiciones que les permitiera proteger los intereses de los artesanos y conservar a la vez la calidad y originalidad de las piezas (Peón y Cortina 1973).

Los gremios en la época colonial sirvieron para que los grupos de artesanos conservaran una parte importante de la producción dentro de sus oficios. Particularmente, los gremios de la ciudad de Puebla eran para ese entonces los más activos y organizados de América, situación que les permitió establecer cierta exclusividad social y racial de los diversos oficios. Dichos gremios contribuyeron al surgimiento de una «coalición proteccionista, asegurando la supervivencia de industrias que de otra manera habrían sucumbido a la competencia extranjera» (Thomson, 2002: 163).

El 5 de agosto de 1652, los maestros loceros gestionaron ante el virrey la autorización para redactar sus ordenanzas y reglamentar su oficio (Cervantes 1939). En dichas ordenanzas se especificaban las normas internas que debían seguir, las cuales iban desde las obligaciones de los aprendices y los maestros hasta el proceso de producción y calidad de la loza. Por tanto, las ordenanzas se dividieron en dos partes, «...una en la que se establecían las condiciones legales del artesano y la otra que se refiere a la calidad del producto y su elaboración» (Huerta 1992: 13). Con lo que respecta al desempeño del oficio se estableció que ninguna persona podía ser alfarero sin estar examinada por los alcaldes y veedores ${ }^{5}$ que eran electos cada año por los maestros loceros.

Los gremios y sus ordenanzas se convirtieron en instituciones que establecían las reglas y las normas para la coordinación del mercado de la loza y sobre todo para su protección durante la colonia. En general los gremios surgieron como una respuesta a la contracción del mercado para los productos manufactureros de la ciudad provocado por la prohibición del comercio intercolonial y la disminución de la producción de plata (Thomson 2002). El gremio de los talaveranos no solo logró el establecimiento de reglas y normas para la elaboración de la artesanía, sino que también consiguió el apoyo jurídico del Estado con lo que aseguraron su estabilidad social y económica. 
El privilegio de pertenecer al gremio de los loceros se hizo evidente con la conformación de su hermandad o cofradía. Dicha hermandad fue creada al inicio del siglo XVII en la iglesia de San Antonio Abad y San Amador. ${ }^{6}$ La finalidad de esta organización consistió en fomentar la ayuda mutua entre los loceros en épocas difíciles tales como: enfermedades, escasez del trabajo, fallecimiento del artesano, en cuyo caso se ayudaba a la viuda y a los hijos $^{7}$ (Cruz 1960). Lo anterior muestra la importancia que tuvieron las ordenanzas del gremio durante el siglo XVII y principios del siglo XVIII, ya que garantizaron la enseñanza y trasmisión del oficio, además de la calidad y la venta de sus productos.

\section{EL INICIO DE UNA TRADICIÓN}

Las cualidades de la loza, especificadas en las ordenanzas, dieron origen a la clasificación de tres géneros de loza: común, ${ }^{8}$ entrefina y fina. Las tres se agruparon bajo la categoría de loza estannífera (Cortina 1999).

La loza común y blanca comprende aquellos artículos destinados al uso de la cocina, platos y vasos modestos para mesa los cuales eran decorados de manera sencilla en colores verdes y con pocos toques de azul (Cortina 1999). La loza entrefina era de mejor calidad, sus productos eran generalmente tazones y platos para mesa, y según los inventarios de algunas locerías de la época costaba la tercera parte de la loza fina (Cervantes 1939). Por su parte la loza fina tenía la característica de no ser clasificada ni producida en serie ya que se hacía de acuerdo con las necesidades del cliente, quien decidía el tamaño, el tipo de pieza y la decoración que debía llevar. Esto explica los precios elevados de la loza y los diferentes tamaños, formas y dibujos de esta época.

La porcelana china también fue objeto de gran demanda entre las personas acaudaladas, lo que dio lugar a una nueva categoría de loza, denominada loza refina. El color de la loza refina debía ser elaborado de un azul subido y realzado, además se pintaba con puntas negras y campos de colores (Cervantes 1939).

El color azul cobró singular importancia en el decorado de la loza poblana ya fuese común o fina, lo que molestó a la mayoría de los loceros ya que los «polvos azules» 
eran muy costosos. Por ello, los loceros propusieron que la loza fina y refina llevara este color y las lozas de menor calidad llevaran un «color inferior», menos subido de tono (Cortina 1989). Es necesario mencionar que sólo una parte de la influencia china fue trabajada en Puebla ya que el típico diseño chino de jardín oriental que enmarcaba un ave fénix fue sustituido por flores y una silueta de pájaro, la cual, dependiendo de la calidad de la loza, era enriquecida con figuras mejor detalladas (Cortina 1989: 66). De esta manera, en la ciudad de Puebla el color azul y los temas chinescos fueron adquiriendo un manejo más tosco de los materiales y los motivos para decorar (Cortina 1989).

En las ordenanzas también se pedía que cada maestro alfarero tuviera una señal o sello para marcar cada obra producida. Dicho sello se registraba y aparecía en la carta de examen para que no pudiera variar. La marca de los alfareros era «sumamente vigilada» para evitar el fraude y el desprestigio de los maestros loceros (Huerta 1992). Asimismo se estableció que si se falsificaba alguna de las firmas de los maestros loceros, se cobraría con los bienes de las personas que incurrieran en dicho delito. Las ordenanzas, no solo protegían la originalidad y calidad de la mercancía, también tenían cuidado con la venta de la loza, la cual se vendía en tiendas públicas y plazas, y únicamente a los maestros loceros se les permitió la venta en las $\operatorname{casas}^{9}$ (Cervantes 1939, t. I).

Si bien el gremio de los loceros era relativamente pequeño ${ }^{10}$ fue una medida que permitió que la industria creciera y tomara renombre. Las piezas producidas en la ciudad eran solicitadas en toda la República, Puebla entonces se asoció definitivamente con la fabricación de la loza más bella, con la de mejor calidad y durabilidad. De esta manera la talavera tuvo un periodo de auge, el cual Atle Baber (citado en Palacios 1917: 656) considera la edad de oro de la talavera que comprende los años de 1650 a 1750. Una gran parte de este periodo contó con las protecciones del gremio de los loceros que se organizó entre 1673 y 1676. Para finales del siglo XVIII y principios del siglo XIX se debilita el sistema colonial que finalmente concluyó en la guerra de independencia. ${ }^{11} \mathrm{La}$ nueva constitución erradicó los gremios y revocó las ordenanzas de la cerámica, lo que generó el surgimiento de nuevos diseños, formas y colores de piezas policromadas. 
Esta situación se mantuvo hasta mediados del siglo XIX cuando se promovió la importación de la cerámica europea, particularmente inglesa y francesa, la cual, debido a su elaboración y decoración con métodos modernos como el transfer-printed —impresión trasferida — permitía la elaboración de varias piezas a la vez que evitaba el pintado a mano. Debido a esta técnica los precios de las piezas eran mucho más baratos, lo que afectó severamente a la mayoría de los centros productores de América, entre ellos Puebla (Cortina 1999). El número de fábricas de loza fina se redujo de 16 a 10 entre los censos de 1794 y 1820. Sin embargo, para 1833 existían 10 fábricas de loza fina y 28 de loza más corriente (Thomson 2002). La incapacidad para competir con las importaciones extranjeras, aun con «técnicas modernas» originó que para 1908 existieran únicamente seis locerías, propiedad de Dimas Uriarte, Luis Guevara, Ignacio Romero, J. M. Sánchez y Antonio Espinosa cuya producción era de «loza utilitaria y azulejos carentes enteramente de mérito artístico» (Baber, citado por Cortina 1999: 23).

En 1930 se desarrollaron varias innovaciones tecnológicas para la industria de la loza, las cuales se pensaba sustituirían la organización de la producción prácticamente artesanal de los maestros loceros. Se estableció una fábrica llamada Fábrica de Sajonia Poblana, que trabajaba con tecnología europea, sin embargo dicho proyecto falló principalmente por los elevados costos de la materia prima. No obstante, se logró que el proceso de fabricación que normalmente llevaba hasta seis meses se realizara en una semana, situación que no evitó el quiebre de la fábrica, la cual cabe mencionar tardó más de tres años en consolidarse (Thomson 2002).

\section{LA CERÁMICA DE TALAVERA DEL XX}

Las circunstancias para la producción de talavera a inicios del siglo XX no eran nada favorables. Sin embargo, el español Enrique Luis Ventosa observó que la región contaba con el material necesario para la producción de talavera y comenzó a trabajar en el taller de Antonio Espinosa, para posteriormente en el de Isauro Uriarte (Ventosa 1971). Ventosa rescata el azul oscuro y los motivos tradicionales de la Talavera de Puebla. Otros talleres lo siguen, generando el resurgimiento de la actividad y fabricando todo tipo de piezas (Cortina 1999). 
Con la llegada de Ventosa a la ciudad de Puebla y el rescate de los estilos chinescos que durante siglos caracterizaron a la talavera de esta ciudad poblana, el taller de talavera de Isauro Uriarte se estableció como uno de los talleres de mayor importancia. El taller requirió de un gran número de trabajadores procedentes principalmente de la ciudad, no obstante también comenzó a contratar artesanos de los estados aledaños; este fue el caso de varios artesanos de San Pablo del Monte, Tlaxcala, que aprendieron el oficio en el taller Uriarte.

Los artesanos de Puebla y San Pablo del Monte aprendieron la elaboración de la talavera al participar en las distintas etapas de su producción, lo que les permitió adquirir habilidades suficientes para abrir su propio taller.

La trasferencia del conocimiento del oficio —o mejor dicho, conocimiento tácitoposibilitó la apertura de pequeños talleres de cerámica tanto en la ciudad de Puebla como en San Pablo del Monte, Tlaxcala, lo que estableció un segundo periodo de auge del sistema productivo de talavera. El conocimiento tácito se difundió con la contratación, en estos nuevos talleres, de nuevos artesanos que a su vez aprendieron a elaborar la talavera (véase diagrama 1) 
Diagrama 1. Conformación del sistema productivo de la talavera

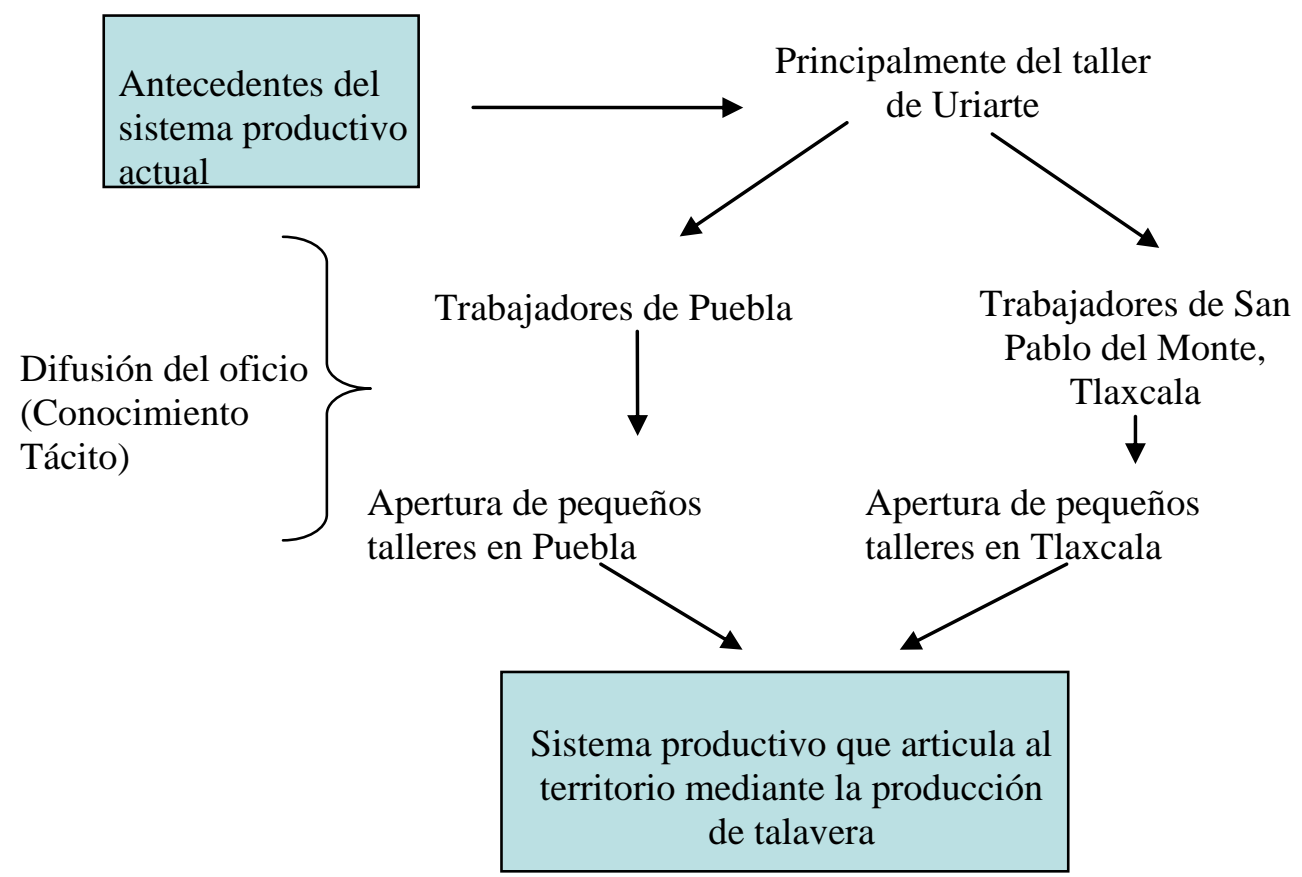

Fuente: elaboración propia

Hoy día, la revalorización de la talavera se debe principalmente a la dificultad de encontrar loza estannífera que no sea fabricada en serie. En México encontramos este tipo de loza en las ciudades de Jalisco, Guanajuato, Hidalgo, Estado de México, Tlaxcala, Distrito Federal y Puebla. Sin embargo, es en la ciudad de Puebla y el municipio de San Pablo del Monte, en Tlaxcala, donde puede admirarse la creciente importancia de esta loza, prueba de ello es la apertura de varias fábricas a finales del siglo pasado.

\section{EL SISTEMA PRODUCTIVO LOCAL DE TALAVERA: LAS DIVERSAS RELACIONES} SOCIOPRODUCTIVAS DE PUEBLA Y SAN PABLO DEL MONTE, TLAXCALA

A principios del siglo XXI, en la llamada «zona de talavera» ${ }^{12}$, identificamos tres grupos de ceramistas que integran el conjunto de relaciones o redes que definen el sistema productivo que analizamos. En primer lugar encontramos el grupo perteneciente a la ciudad de Puebla conformado por los productores de cerámica de talavera 
verificados hasta el año 2005, por el Consejo Regulador de Talavera, CRTAL; ${ }^{13}$ a este grupo lo denominamos Productores de cerámica de talavera certificada.

Un segundo grupo de ceramistas es el que se localiza en San Pablo del Monte, Tlaxcala; el proceso de producción y acabado de la pieza es semejante al de los productores de Puebla. Sin embargo, aún no han conseguido la certificación, es decir, no han logrado la autenticación de sus productos como talavera. A este grupo lo denominamos Productores de cerámica no-talavera.

El tercer grupo de ceramistas que identificamos se encuentra localizado tanto en los municipios de la ciudad de Puebla como en San Pablo del Monte, Tlaxcala. El trabajo de estos artesanos es también muy similar al que llevan a cabo los otros dos productores de cerámica, pero en este caso la diferencia radica principalmente en los colores industriales aplicados sobre una base de esmalte de color blanco también fabricada industrialmente. A este grupo de artesanos los llamamos Productores de cerámica blanca, por el color que predomina de fondo en dichas artesanías.

En cierta forma, estos tres grupos de productores elaboran diferentes tipos de lozas similares a las que se producían durante la colonia mediante la clasificación de loza común, fina y refina. En la actualidad, el Consejo Regulador de la Talavera y la norma 132 reforzaron la diferenciación entre los productores, sus mercancías y los mercados a los que se dirigen.

\section{EL CAPITAL SOCIAL Y LAS REDES SOCIALES: LA APERTURA DEL TALLER}

Por más de cuatro siglos la talavera se ha elaborado artesanalmente en la ciudad de Puebla y Tlaxcala, de tal manera que la tradición alfarera ha sido un elemento crucial en la conformación del capital humano que ha caracterizado históricamente el entorno local. Las habilidades adquiridas por los artesanos de esos primeros alfares se convirtieron en un bien colectivo que ha sido trasmitido de generación en generación por los artesanos locales. Dichas habilidades en el trabajo de la cerámica forman parte del conocimiento tácito socialmente desarrollado, el cual ha contribuido a la conformación del capital social que caracteriza la organización de este sistema 
productivo. Tanto el conocimiento del oficio como las redes familiares, en primera instancia son los elementos que han contribuido a la organización de las empresas familiares en el área de estudio.

En el trabajo de campo encontramos que la mayoría de los productores abrieron su taller gracias al capital humano y a las relaciones que previamente habían establecido con amigos y conocidos de otros talleres de talavera. Al respecto la Sra. Norma Martínez, artesana y administradora de un taller de cerámica blanca de la ciudad de Puebla, menciona lo siguiente:

\footnotetext{
...Estuve trabajando por 16 años; luego de ahí nos cambiamos a otra fábrica, ahí estuve 8 años y luego nos salimos ... el apoyo para salirnos de los talleres y abrir el nuestro lo recibimos de un compadre que trabajaba en la producción de cerámica. Un tiempo trabajamos con él, hasta que un día me dijo: señora, ¿por qué no pone su taller?, usted sabe decorar muy bien, sabe su esposo y su hermana y sus hijos. Entonces mi compadre - en ese tiempo aún no éramos compadresme dijo ponga su taller, yo le ayudo, como él sabía todo el proceso nos asesoró y nos dijo qué comprar y qué no. Yo con la experiencia que ya tenía pues ya sabía más o menos los materiales, pero siempre hay algo más que saber...
}

La decisión de abrir un taller de talavera no es algo que se lleva a cabo de un día a otro, el contexto social en el que se desarrolla un individuo influye en gran medida sobre su futuro laboral. De aquí la importancia que tiene el conocimiento tácito del que dispone la comunidad local, el cual permite a los miembros de la misma familiarizarse con el proceso artesanal de la loza. En este caso las relaciones de confianza entre los actores y la difusión del conocimiento tácito hacen que la proximidad sociocultural sea importante (Salazar 2004).

Los productores de talavera han aprovechado, además del conocimiento tácito, los conocimientos adquiridos a lo largo de su educación, ya que la mayoría de los artesanos que entrevistamos tiene una profesión, lo que sin duda alguna le da una ventaja frente a otros ceramistas ya que les ha facilitado la organización no solo dentro de la empresa sino fuera de ella. Así, encontramos que estos pequeños productores han tenido la capacidad de organizarse para coexistir en un ambiente de cooperación y competencia. 


\section{COOPERACIÓN Y COMPETENCIA}

El primer elemento de competencia que puede encontrarse en nuestra área de estudio consiste en la diferencia de precios de las mercancías entre los productores de cerámica de talavera de Puebla y los productores de cerámica no-talavera del municipio de San Pablo del Monte, Tlaxcala. Esta situación inicia en 1999 cuando se establece la diferencia entre productores de talavera certificados — cerámica de talavera- y no certificados — cerámica no-talavera—, ya que los primeros tenían que pagar no solo la cuota por estar asociados a CRTAL, sino que además debían cubrir el costo de la certificación y las pruebas de laboratorio, lo que incrementaba el precio de la artesanía.

Otra diferencia entre los productores de cerámica no-talavera de San Pablo del Monte Tlaxcala y los productores de talavera de la ciudad de Puebla es que estos últimos, cuando formaron parte del CRTAL, fueron regulados por la norma 132, la cual además de definir las características de la producción de talavera prohibió a los productores vender otro tipo de cerámica en sus locales. Los productores de San Pablo del Monte al no encontrarse regulados por la norma se dedicaron a fabricar y vender cerámica notalavera, cerámica blanca e incluso cerámica que traen de otras regiones. Por lo tanto, en un mismo local comercial pueden vender tres tipos de artesanía, diferenciadas por su calidad, diseño, origen y precio. El mercado que abarcan los productores de San Pablo del Monte es mayor y si bien sus productos tienen un precio menor el volumen de venta de otros productos compensa sus ganancias.

Por otra parte, el aumento en el número de talleres de cerámica no-talavera es otro factor que ha generado mayor competencia y por lo tanto también ha influido en la disminución de los precios en las artesanías de San Pablo del Monte y de Puebla. En años recientes se han abierto aproximadamente 70 talleres $^{14}$ que en general se dedican a elaborar cerámica no-talavera y cerámica blanca a precios muy bajos; si bien la calidad que tiene la artesanía no es muy buena, cuenta con un mercado muy amplio.

Otro aspecto que genera cierto nivel de rivalidad entre los productores se relaciona con el control de la información sobre la fórmula - la combinación más conveniente de 
minerales que facilita la producción de la artesanía - que se utiliza en el proceso de producción. Una constante que encontramos entre todos los productores que entrevistamos es que podríamos hablar prácticamente de cualquier cosa, menos de las cantidades exactas para la elaboración de pinturas, tiempos de cocción, de reposo de barro, etc. La gran mayoría de los productores, sobre todo aquellos que han abierto sus puertas en la década de los noventa, mencionaron que tuvieron que pagar por la fórmula para elaborar talavera.

Si bien la idea de elaborar talavera parte del hecho de haber crecido en un ambiente artesanal y haberse familiarizado con el proceso productivo, de todas formas es necesario echar mano de las redes sociales con las que se cuenta para iniciar y organizar un taller.

La posibilidad de formar parte y aprovechar un conjunto de redes sociales que facilitan las relaciones de cooperación, permitiendo al mismo tiempo cierto nivel de competencia en el mercado, no es fácil de encontrar en cualquier territorio. En nuestro caso, esta situación se facilita debido a dos aspectos: en primer lugar es posible diferenciar la talavera que se produce entre un taller y otro, por tratarse de una artesanía. Es decir, aunque las piezas de talavera deban cumplir con ciertas normas que definen su producción, existen diferencias sustanciales en cuanto al diseño de las mismas, tamaño y color debido al carácter único de cada pieza. Margarita Reyes, administradora de un taller de talavera localizado en San Andrés Cholula, Puebla, menciona lo siguiente:

\footnotetext{
...no existe esa, por llamarlo de alguna manera, rivalidad, porque el trabajo es diferente aunque sea la misma técnica, por ejemplo: Talavera de la Luz hace unos murales enormes y se ha distinguido por eso o el taller de la señora Tovar que elabora piezas con relieve pero del mismo barro. Nosotros en cambio hacemos diseños modernos ... entonces cada quien tiene su estilo.
}

El segundo aspecto consiste en el hecho de que en la ciudad de Puebla hay un mercado muy amplio el cual difícilmente se ha cubierto debido a la escasa cantidad de talaveranos en la ciudad. La competencia está representada por los productores de cerámica no-talavera e incluso los productores de cerámica blanca, ya que ellos cubren 
otro sector del mercado no atendido por los talaveranos, es decir, abarcan un mercado más barato.

\section{INSUMOS, PRODUCCIÓN Y REDES COMERCIALES}

El sistema productivo de la talavera ha dado lugar a una gran variedad de redes sociales y económicas que se encuentran entrelazadas por las distintas fases de la producción, que van desde la obtención de las materias primas hasta la comercialización de las mercancías. Veamos con mayor detalle algunas características de las redes que conforman el sistema productivo.

\section{MATERIAS PRIMAS}

Las materias primas en la producción de la talavera son; a) los barros — rojo y blanco-, b) la calerna, arenilla, plomo y estaño para elaborar el esmalte con el que se recubren los jagüetes, ${ }^{15}$ c) la elaboración de colores para decorar la pieza, colores elaborados con base en «óxidos» o materiales extraídos de la naturaleza. Entre los principales minerales ocupados para la elaboración de la talavera encontramos: óxido de cobalto, la arenilla, la caspa de hoja de lata, el cristal en polvo, la piedra colorada o de riñón. ${ }^{16}$

En el año 1998 se establece la norma 132, y en 1999 se crea CRTAL. A similitud de la norma de los gremios del siglo VXII que regulaba la producción de la talavera, la norma 132 establece que las materias primas únicamente deben proceder de la «zona talavera» en el estado de Puebla. La regulación de la producción genera una red de insumos al interior de la región en donde, prácticamente, todos los talaveranos de Puebla tienen los mismos distribuidores quienes les llevan las materias primas de municipios poblanos. En las entrevistas realizadas a otros ceramistas de Puebla — productores de cerámica no blanca- mencionan que los barros que utilizan los productores de talavera, si bien son del estado de Puebla, no siempre provienen de los municipios de la llamada «zona talavera», como exige la norma 132.

Las relaciones que se establecen entre los productores y entre los proveedores son muy importantes para asegurar la adquisición de barros de buena calidad o simplemente para asegurar su adquisición. Los productores en general manifestaron que no tenían ningún 
problema para adquirir materias primas, pero sí manifestaron que era importante «conocer» quién les podría vender las materias primas. Al respecto comentó el artesano Venancio Pérez: «...es bueno conocer quién está en esto, porque si tienes una necesidad ya sabes a quién recurrir, aquí todo se sabe con quién sí y con quién no...».

Así, prácticamente desde el comienzo, la compra de las materias primas se convierte en un factor decisivo para la obtención de una artesanía con mayor calidad. Las relaciones de amistad y de confianza que establecen los artesanos con los proveedores facilitan tanto la apertura como la permanencia de los talleres en el mercado. Asimismo, las relaciones de amistad y de confianza que han construido con otros productores han permitido generar un ambiente de cooperación en cuanto a la adquisición o intercambio de materias primas.

\section{LOS ARTESANOS Y EL PROCESO PRODUCTIVO}

El proceso de producción de la talavera poblana es sumamente laborioso que se lleva en promedio de cuatro meses a un año, dependiendo de la complejidad del diseño y de la calidad de los barros. La elaboración de talavera en su conjunto pasa por ocho procesos ${ }^{17}$ que abarcan desde la adquisición de las materias primas hasta la venta de la artesanía.

Los talleres que estudiamos son de carácter familiar y por lo mismo ésta participa desde la producción a la comercialización de los productos. Los artesanos entrevistados hicieron énfasis en su conocimiento y participación en cada una de las etapas del proceso de elaboración de la talavera; de hecho es común que los artesanos participen en más de una tarea e incluso, si la situación lo amerita, puedan sustituir a un trabajador ya sea éste un familiar o asalariado.

El papel de cada uno de los integrantes de la familia es importante para el buen funcionamiento del taller. En el trabajo de campo apreciamos que las mujeres generalmente se emplean en el esmaltado y el decorado de la artesanía por considerarse un trabajo de precisión y a su vez de delicadeza, ${ }^{18}$ asimismo, en el caso de aquellas que cuentan con estudios - mujeres identificadas principalmente en talleres de la ciudad de 
Puebla - se ocupan también en la administración del taller familiar. Por su parte, los hombres son quienes realizan la elaboración de pinturas, el torneado, cocción y comercialización de las piezas.

En el caso de San Pablo del Monte, la mayoría de los artesanos son ceramistas de segunda generación, esto significa que sus padres fueron quienes les enseñaron el oficio. Algunos de estos artesanos, al contar con un mayor nivel de educación, no solo están innovando en diseños de la artesanía, también buscan nuevas formas de organización al interior de los talleres.

En los talleres certificados de Puebla, de acuerdo con la norma 132, los trabajadores son originarios de la ciudad de Puebla. La finalidad de este requisito tiene que ver con la conservación de lo «secretos de producción», o en otras palabras con la retención del conocimiento tácito en el espacio local. En realidad esta situación no ha podido controlarse, muestra de ello es el crecimiento de los talleres en el municipio vecino de San Pablo del Monte, organizados por trabajadores que aprendieron el oficio en talleres poblanos mucho antes de la organización CRTAL.

La rotación del personal en la ciudad de Puebla y San Pablo del Monte, Tlaxcala, es alta, lo que obliga a la continua capacitación de nuevo personal y, por tanto, la trasmisión del conocimiento del proceso de producción de la talavera. Sin embargo observamos que dicha rotación no es tan frecuente en cuanto a los pintores(as) ya que estos(as) son altamente valorados debido a la experiencia que tienen en la aplicación e innovación de diseños.

En las entrevistas los productores mencionaron la importancia de tener en el taller a un pintor reconocido, el cual debe cumplir con las siguientes características: a) que realice nuevos diseños - o diseños contemporáneos-, y que por supuesto estos sean aceptados por el comprador; b) tenga varios años de experiencia trabajando con la artesanía de talavera, y c) que realice con precisión y belleza los diseños tradicionales.

Al respecto la Lic. Ana Cabrera comentó lo siguiente: 


\begin{abstract}
...yo generalmente los empleo sin que sepan nada, únicamente los pintores son los que se encuentran previamente calificados, ellos vienen sabiendo el oficio, casi siempre provienen de familias artesanas o de otras fábricas donde aprendieron el proceso. Entonces lo único que tienen que aprender es el modo de pintar nuestros diseños, porque yo creo que cada taller tiene su forma y sus diseños ... así poco a poco van aprendiendo el modo de pintar de aquí.
\end{abstract}

En general los talleres de Puebla y San Pablo del Monte son talleres caracterizados por medios de producción — hornos, tornos — propiedad del artesano en donde la mano de obra familiar se suma a la mano de obra asalariada. Los trabajadores asalariados no rebasan el número de familiares involucrados en el proceso de producción, sin embargo, en temporadas difíciles estos últimos pueden disminuir.

\title{
LA COMERCIALIZACIÓN DE LA ARTESANÍA
}

Desde la época colonial la localización de la ciudad de Puebla favoreció la rápida distribución de las manufacturas por toda la Nueva España, situación que en el caso de la alfarería continúa siendo aprovechada para la distribución de la artesanía, sobre todo con lo que respecta a la ciudad de México y Estados Unidos.

Los talaveranos poblanos, si bien le apuestan al mercado local, consideran que el verdadero mercado se encuentra fuera de México y que las ganancias se obtienen en la exportación. Por ello han intentado colocar sus productos en España e Italia, lugares que tradicionalmente se han dedicado a la elaboración y fabricación de cerámica. Asimismo, han intentado abrir su mercado exponiendo sus productos tanto en ferias y mercados locales, como en museos de reconocimiento nacional, tal es el caso del museo Franz Mayer localizado en la ciudad de México o museos internacionales de Italia, España y China.

La exposición de piezas en museos tiene la finalidad de: a) generar un nicho de mercado exclusivo de coleccionistas de piezas originales, y b) informar acerca del proceso productivo de la talavera certificada. Los artesanos poblanos apuestan a la difusión para generar interés en la artesanía y por supuesto para colocar sus productos de manera más eficiente en el mercado. Al respecto, el Dr. Adrián Aguirre mencionó lo siguiente: 
...nos hace falta difusión, fui presidente del consejo regulador, hice un simposium internacional, hice un video, difundí la importancia de la denominación de origen a nivel de radio, prensa televisión, todos los medios conocidos y por haber. ¿Por qué?, porque yo creo en la bondad del producto, no como un producto de punto de venta nada más, para que tú me consigas y te intereses por comprar un producto que aparentemente es caro, o sea caro en realidad, pues debes conocer el valor histórico para que puedas decir si lo vale ... Por eso es una obligación difundir el conocimiento de la certificación de ese tipo de productos ... en el simposium tuvimos una audiencia de más de trescientas gentes por cada día. Nos interesaba que la gente conociera históricamente desde donde viene, desde cuando viene, y todo su valor histórico, yo creo que sí debe tener resultados. Pero no se puede tener un resultado de la noche a la mañana y que el día de mañana empiece yo a vender todo el producto, no es cierto, este es un proceso lento...

Los talaveranos poblanos buscan, por lo tanto, un mercado y un comprador que se interese por los productos «únicos» elaborados cien por ciento a mano. En este sentido, si bien el fenómeno de la globalización habla de una «homogeneización» de los productos y del consumo, la diferenciación de los productos de acuerdo con las particularidades culturales e históricas que se expresan en ellos, es un aspecto que detona otros mecanismos de comercialización.

Los mercados a los que se dirigen tanto los talaveranos del estado de Puebla como los productores de cerámica-no talavera del estado de Tlaxcala son mercados diferenciados ya que mientras los primeros se enfocan a un mercado nacional e internacional, ${ }^{19}$ los productores de San Pablo del Monte se dirigen a uno de carácter local y nacional, distribuyendo sus artesanías en lugares de atracción turística como Cancún, Cozumel, Baja California Sur, Puerto Vallarta y Cuernavaca. Sin embargo existen excepciones, ya que algunos productores de San Pablo del Monte han vendido sus mercancías por el valor agregado de libres de plomo a, por ejemplo, Japón y Dinamarca.

Los productores de cerámica de talavera llevan a cabo la elaboración de las piezas de manera completa, tanto la mezcla de los barros —extraídos principalmente de la zona talavera - como la elaboración de colores se da completamente de manera manual, de ahí el costo de la artesanía. Debido a las regulaciones establecidas en la norma 132, los productores definieron el control de todo el proceso de producción y comercialización 
para conservar la certificación que les otorga CRTL. Si bien las regulaciones que ellos mismos establecieron para controlar y coordinar la producción de talavera los coloca en un mercado exclusivo de clientes, también limita su comercialización debido a que no consideraron el control del plomo en la elaboración de la norma 132. Este es un tema que actualmente les obliga a replantearse la revisión de las características definidas en la norma, las cuales han resultado muy rígidas para el adecuado funcionamiento de la producción de una artesanía que ha demostrado tener un buen potencial de distribución en el mercado (figura 1).

Figura 1. Cadenas de producción y comercialización de los productores de cerámica de talavera certificada

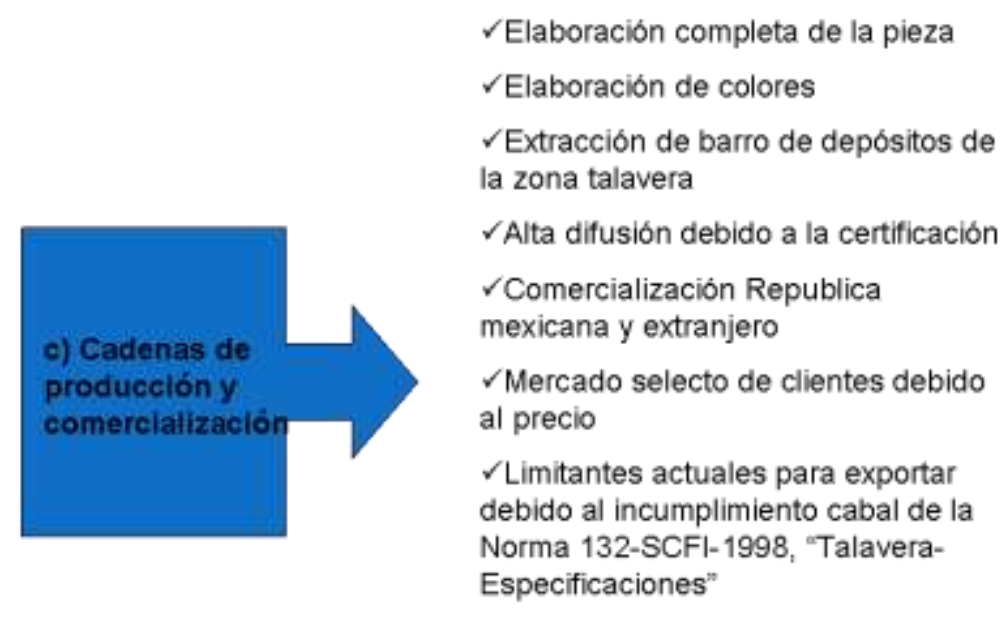

Fuente: elaboración propia.

Con respecto a los productores de cerámica no-talavera (Figura 2) observamos que tienen un amplio mercado debido al bajo costo de sus artesanías, en determinado momento pueden acceder a varios mercados de distribución de las mismas ya que así como elaboran ceramica-no talavera, también elaboran cerámica blanca. 
Figura 2. Cadenas de producción y comercialización de los productores de cerámica no-talavera

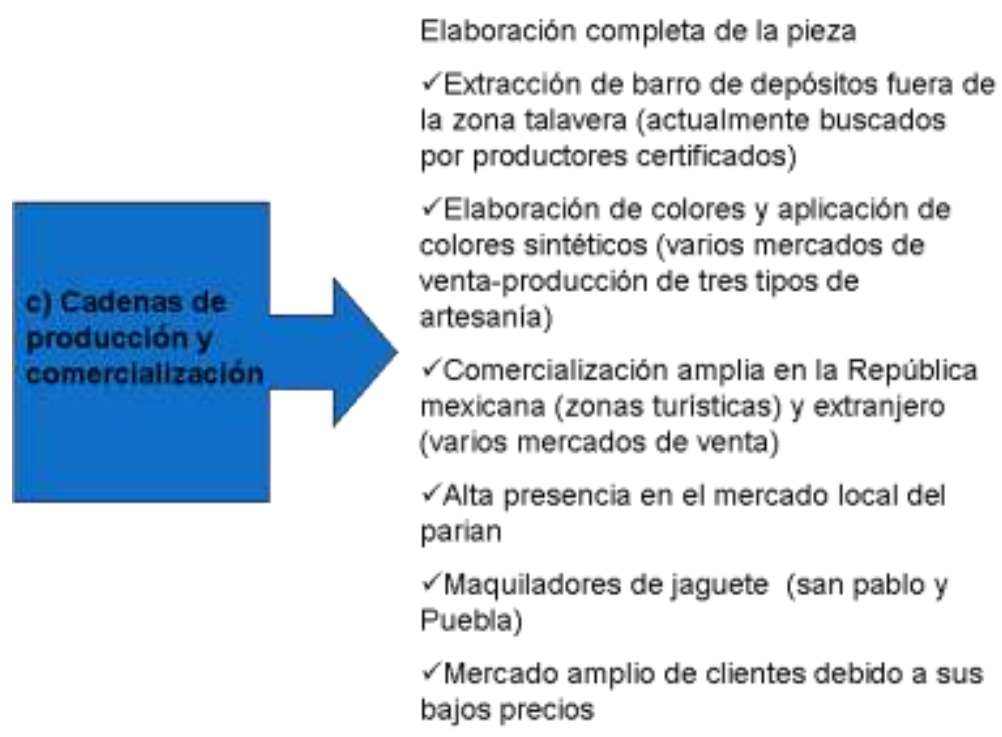

Fuente: elaboración propia.

En cuanto a los productores de cerámica blanca (figura 3), localizados tanto en Puebla, como en San Pablo del Monte, Tlaxcala podemos decir que aunque su distribución sea principalmente de carácter local sus productos también son distribuidos a nivel nacional y exportados por medio del Fondo Nacional para el Fomento de la Artesanías, Fonart, debido a que la elaboración de sus productos está completamente libre de plomo.

Figura 3. Cadenas de producción y comercialización de los productores de cerámica blanca

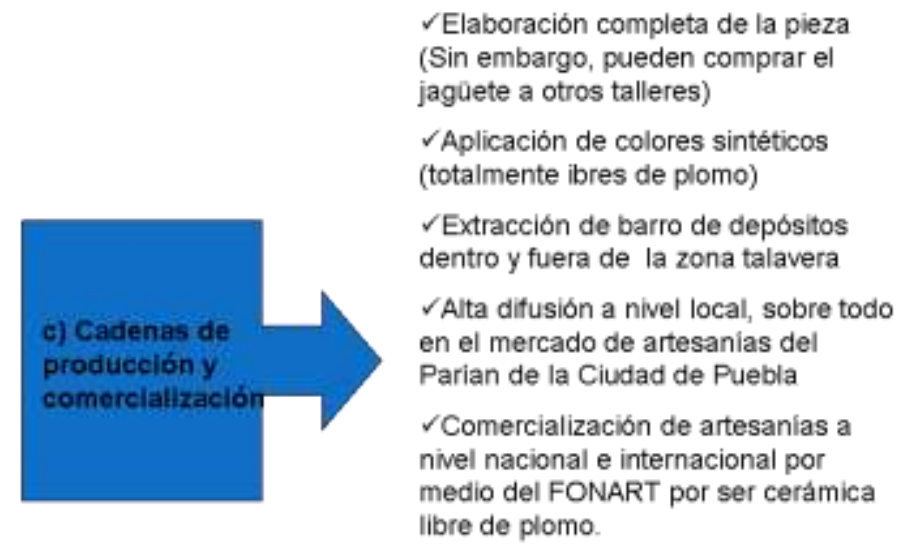

Fuente: elaboración propia. 


\section{CONSIDERACIONES FINALES}

En nuestra región de estudio, encontramos una aglomeración de talleres familiares dedicados a la elaboración artesanal de la talavera la cual ha generado desde mediados del siglo XVI un conjunto de redes sociales y económicas así como instituciones que permiten hablar de un sistema productivo local.

La aglomeración de diversos talleres de productores de talavera ha facilitado el aprendizaje, la difusión y reproducción del oficio en tres momentos históricos importantes:

a) El primer periodo se produce a inicios de la colonia con la llegada de los franciscanos a la ciudad de Puebla de los Ángeles a mediados del siglo XVI, quienes enseñaron el oficio a los indígenas originarios de la región los cuales combinaban la agricultura con la alfarería.

b) El segundo momento se presenta principalmente en la década de los setenta del siglo XX, situación que se debió en gran parte al artista español Luis Enrique Ventosa, quien formo una asociación con Isauro Uriarte - heredero del taller de talavera Uriarte, la tienda con mayor presencia en el mercado hasta el día de hoy-. Ambos artistas rescataron el estilo chinesco y fueron imitados por los demás talleres de talavera de la ciudad de Puebla, debido al éxito de sus ventas.

c) Finalmente, la etapa más reciente, en la década de los años noventa del siglo XX, cuando a similitud de las ordenanzas del gremio de talavera del siglo XVII se establecen, nuevamente, no solo las normas internas con que se debe de regir el Consejo Regulador de Talavera, CRTAL, sino las normas de elaboración y calidad de las artesanías de talavera (norma 132).

En los tres momentos, la concentración de los artesanos en la región ha facilitado la trasferencia de conocimientos de una generación a otra. El conocimiento tácito es por lo tanto el elemento más importante en la consolidación —en particular- de la unidad productiva, y —en general - del sistema productivo local. En esta lógica, la familia juega un papel relevante en la socialización de dicho conocimiento. 
Así, tanto en Puebla como en San Pablo del Monte, Tlaxcala, observamos que la mayoría de productores proviene de familias que se han dedicado durante décadas a la producción de la artesanía de talavera. Estos productores cuentan con un capital humano y social que les permite ingresar al sistema productivo con ciertas ventajas. La manera en que se valora y percibe el trabajo de los artesanos que convergen en el taller tiene que ver con las reglas y costumbres socializadas en el espacio local, mismas que son aprendidas rápidamente por los productores que no tienen relaciones sociales directamente involucradas en la producción de la artesanía.

El proceso de aprendizaje de los artesanos se da en un contexto de producción y reproducción de hábitos y rutinas que legitiman el proceso productivo. Lo que observamos en el trabajo de campo es que las destrezas que los sujetos adquieren al momento de aprender el oficio, con el tiempo se trasforman en hábitos que son a su vez compartidos con otros talaveranos, convirtiéndose en rutinas o costumbres que dan cuerpo a las instituciones sociales que van integrando a un sistema productivo local; por medio de los gremios, asociaciones de productores, organismos y normas legales (Hodgson 2007: 69). Es así que el proceso de elaboración de la talavera — desde el aprendizaje del oficio, hasta los mercados a los que se dirige la producción - tiene que ver con la reproducción de dichos hábitos y rutinas.

Con lo que respecta a la relación entre los artesanos de ambos estados y tipos de producción, podemos decir que ésta ha sido compleja principalmente por la tendencia a creer: 1) que la competencia tiene que ver de manera exclusiva con el precio final de la artesanía, 2) que la competencia sólo existe en el ámbito local, específicamente nos referimos a la competencia que representa la producción y venta de la artesanía de San Pablo del Monte, Tlaxcala, para los productores de la ciudad de Puebla. De hecho, este fue el principal motivo por el que los artesanos de Puebla buscaron la protección de la artesanía mediante la Norma 132 y la organización del Consejo Regulador de la Talavera. 
En cuanto a la relación de competencia entre los artesanos al interior de la ciudad de Puebla como los que convergen en el municipio de San Pablo del Monte, Tlaxcala, se evidenció la tendencia a la autosuficiencia relacionada de manera directa con el prestigio del artesano y, por lo tanto, del taller. El prestigio del artesano y la experiencia adquirida por él a través de los años se convierte en un arma de doble filo al momento de la cooperación, dado que así como son reconocidos mediante sus éxitos es difícil que los demás artesanos puedan olvidar un fracaso dificultando en un determinado momento el comportamiento cooperativo. En este sentido, las relaciones de cooperación y competencia se encuentran fuertemente interrelacionadas dependiendo no solo del fin que se persiga, sino de igual manera del contexto social, económico e histórico.

En distintos momentos históricos encontramos variadas formas de configuración de las relaciones de cooperación y competencia entre los productores de cerámica. La organización de los gremios de artesanos en el siglo XVI ilustra una etapa muy importante de coordinación de los mercados locales novohispanos, en relación con los mercados internacionales así como de relaciones de cooperación y competencia entre los productores locales. En el siglo XX, en la década de los noventa, se observa la organización de los talaveranos de la ciudad de Puebla mediante la formación del Consejo Regulador de la Talavera y la Norma 132. Estas últimas instituciones y reglas son una respuesta a la competencia no solo de productos locales, sino también a la de procedencia asiática.

En nuestro estudio, observamos dos momentos importantes en la conformación de las instituciones locales:

1) en el año de 1993, cuando los productores de cerámica de talavera comienzan a organizarse para obtener la Denominación de Origen,

2) en el año 2003, cuando los productores de cerámica no-talavera de San Pablo del Monte, Tlaxcala (organizados desde 1997), son incorporados en la zona de talavera. 
Las organizaciones de productores están construyendo, mediante el aprendizaje individual y colectivo, instituciones y arreglos institucionales que han trasformando el ambiente institucional del espacio local. La denominación de origen talavera, DO4, expresa un conjunto de acuerdos, normas y reglas de organización de un mercado que en su proceso de conformación ha generado un conjunto de acciones colectivas que hoy, todavía, no sabemos si lograrán combinar un adecuado balance entre la cooperación y la competencia entre los pequeños talleres familiares.

Tanto los artesanos de Puebla como los de San Pablo del Monte se están organizando para flexibilizar la Norma 132 en torno a la delimitación de los yacimientos de barros y a la elaboración del esmalte, lo cual resolvería el problema de los niveles de plomo en las artesanías y favorecería la apertura a los mercados internacionales. En este sentido sólo queda esperar que los artesanos logren generar cambios en la Norma 132 y que lleguen a conformar un organismo certificador que les permita establecer lineamientos de producción benéficos tanto para los productores de Puebla como para los productores de San Pablo del Monte.

En síntesis identificamos una atmósfera industrial que permite, entre otras cosas, el aprendizaje colectivo, intercambios informales y cierto dinamismo interno de reproducción y organización del propio sistema. Así, el contexto sociohistórico ha jugado un papel determinante no solo en la aglomeración de productores y unidades productivas, sino del mismo modo en el sentimiento de pertenencia de una comunidad productiva en constante cambio. 


\section{BIBLIOGRAFÍA}

Alburquerque Francisco, 2004, «El enfoque del Desarrollo Económico Local», Cuadernos DEL, n. 1, Buenos aires, en http://www.redel.cl.

Bourdieu, Pierre, 1997, Capital cultural, escuela y espacios social, Siglo XXI, México.

1980, «Le capital social: notes provisoires», Act. Rech. Sci. Soc., n. 31, pp. 2-3.

Castro Efraín, 1989, «Puebla y la Talavera a través de los siglos», en La Talavera de Puebla, Leonor Cortina, Artes de México, n. 3, primavera, México, pp. 32-40.

Caravaca, Inmaculada, 1998, «Los nuevos espacios ganadores y emergentes», Revista EURE,_v. 24, n. 73, Pontificia Universidad Católica de Chile, Santiago de Chile.

Caravaca, Inmaculada y Silva Rocío González Gema, 2005, «Innovación, redes, recursos patrimoniales y desarrollo territorial», Revista Eure, año/v. XXXI, n. 094, Pontificia Universidad Católica de Chile, Santiago de Chile, pp. 5-24.

Castells, Manuel, 1997, «La era de la información. Economía, Sociedad y Cultura», v. 1: La sociedad red, Alianza, Madrid.

Cervantes, Enrique, 1939, Loza blanca y azulejo de Puebla, 2 tomos, Gobierno del estado de Puebla, Secretaría de Cultura, México.

Connors Margaret y Contreras Jaime, 1999, Talavera Poblana: four centuries of a Mexican ceramic tradition, American Society Library of Congress card Catalogue Number 99-07354I.

Cortina, Leonor, 1999, «La Talavera de Puebla», en Talavera contemporánea, Secretaría de Cultura del Estado de Puebla, Universidad de las Américas-Puebla, Uriarte Talavera, Puebla México, pp. 13-25. 
1989, «Loza Achinada», en La Talavera de Puebla, Leonor Cortina, Artes de México, n. 3, primavera, México, pp. 32-40.

Cruz, Francisco, 1960, Las artes y los gremios en la Nueva España, Jus, México.

Diario Oficial de la Federación, 1997, «Declaratoria general de la Denominación de Origen Talavera», primera sección, México, Distrito Federal, pp. 2-7.

2003, «Extracto de la solicitud de modificación a la declaratoria general de protección a la denominación de origen talavera», México, Distrito Federal, pp. 99-100.

Díaz de Cossío, Alberto y Francisco Álvarez, 1982, La cerámica colonial contemporánea, Fondo Nacional para el Fomento de las Artesanías, Fonart, Secretaria de Educación Pública, SEP, México.

Dutrénit, Gabriela, 2001, «El papel de las rutinas en la codificación del conocimiento de la firma», Análisis económico, segundo semestre, año/v. XVII, n. 34, UAM Azcapotzalco, pp. 211-230.

Granovetter, Mark, 1973, «The Strength of Weak Ties», The American Journal of Sociology, v. 78, n. 6, pp. 1360-1380.

Herreros Vázquez, Francisco, 2002, «¿Son las relaciones sociales una fuente de recursos? Una definición de capital social», Papers n. 67, pp. 129-148.

Hodgson, M. Geoffrey, 2007, Economía Institucional y Evolutiva Contemporánea, Universidad Autónoma Metropolitana Cuajimalpa Xochimilco, México.

Hoffman, Carlos, 1922, Verdades y errores acerca de la Talavera Poblana, Imprenta de la Secretaría de Gobernación, México. 
Huerta, Ana Ma., 1992, La alfarería poblana. Siglos XVI y XVII. El gremio y sus ordenanzas, Lecturas Históricas del Estado de Puebla n. 84, Gobierno del estado de Puebla, Secretaría de Cultura, Comisión Puebla V Centenario.

Kury, Armando, 2006, «Innovación tecnológica y sistemas productivos locales», ECONOMIA, UNAM, v. 3, n. 7, enero abril, pp. 131-151.

Klein, Juan-Luis, 2006, «Geografía y desarrollo local», en Tratado de geografía humana, dirigido por Hiernaux y Lindòn, Anthropos, Universidad Autónoma Metropolitana Iztapalapa, México, pp. 303-319.

Liehr, Reinhard, 1993, «El comercio colonial y la Puebla de los Ángeles», en Puebla, textos de su historia, v. II, compilado por Carlos Contreras y Nadia Cruz, Instituto de Investigaciones Dr. José María Luis Mora, México, pp. 192-196.

Luna, Matilde y José Luis Velasco, 2005, «Confianza y desempeño en las redes sociales», Revista Mexicana de Sociología, v. 67, n. 1, enero-marzo, pp. 127-162.

Martin, Ron, 2000, «Institutional Approaches in Economic Geography», en $A$ companion to Economic Geography, editado por Eric Sheppard y Trevor J. Barnes, Blackwell, pp. 75-94.

Méndez, Ricardo, 1997, Geografía económica. La lógica espacial del capitalismo global, Ariel, España.

1998, «Innovación tecnológica y reorganización del espacio industrial: una propuesta metodológica», Eure, v. 24, n. 73, pp. 31-54.

Mora Salas, Minor, 2004, «Hacia una visión sociológica de la acción económica: Desarrollos y desafíos de la sociología económica», en La Sociología Económica: Una lectura desde América Latina, Pozas, María de los Ángeles, Minor Mora Salas y Juan 
Pablo Pérez Sáinz, Cuaderno de Ciencias Sociales, n. 134, FLACSO Costa Rica, pp. $37-$ 64.

Morales, Federico, 2003, «Desarrollo regional sustentable: una reflexión desde las políticas públicas» (en línea), Revista Digital Universitaria, 31 de octubre de 2003.

Nelson Richard y Sampat Bhaven, 2001, «Las instituciones como factor que regula el desempeño económico», Revista de Economía Institucional, n. 5, Segundo Semestre, pp. 17-51.

Ostrom, Elinor y T. K. Ahn, 2003, «Una perspectiva del capital social desde las ciencias sociales: capital social y acción colectiva», Revista Mexicana de Sociología, año LXV, n. 1, enero marzo, México, pp. 155-233.

Palacios, Enrique, 1917, Puebla. Su territorio y sus habitantes, Departamento de talleres gráficos de la Secretaría de Fomento, México.

Peón, Alejandra y Leonor Cortina, 1973, Talavera de Puebla, editorial financiera Comermex, México.

Pérez, Carmen y Ovando Carlos, 1979, Talavera Poblana, Fomento Cultural Banamex, A. C., Pinoteca Marqués del Jaral de Barrio, México.

Pérez, Francisco, 1971, «La fundación de la ciudad de Puebla», en Puebla, azulejo mexicano, compilado por Rafael Carrasco, H. Ayuntamiento de Puebla, Relaciones Públicas, Puebla México, pp. 5-20.

Peñafiel, Antonio, 1910, Loza de Talavera de Puebla, época colonial y moderna, Secretaría de Fomento, México. 
Quintana, José, 1971, «Visiones de Puebla», en Puebla, azulejo mexicano, compilado por Rafael Carrasco, H. Ayuntamiento de Puebla, Relaciones Públicas, Puebla, México, pp. 21-37.

Rosales, Rocío, 2010, «Aprendizaje colectivo, redes sociales e instituciones. Hacia una nueva geografía económica», en Los giros de la Geografía Humana: Desafíos y Horizontes, dirigido por Alicia Lindón y Daniel Hiernaux, Antrophos, Universidad Autónoma Metropolitana Iztapalapa, en edición.

Sabino, Carlos, 1991, Diccionario de Economía y Finanzas, Editorial Panapo, Caracas.

Salazar, José, 2004, «Algunas reflexiones sobre la gestión del conocimiento en las empresas», Intangible capital, n. 2, julio-agosto, Barcelona, España.

Semitiel García, María y Pedro Noguera Méndez, 2004, «Los sistemas productivos regionales desde la perspectiva del análisis de redes», Revista hispana para el análisis de redes sociales, v. $6, \mathrm{n} .3$, en http://revista-redes.rediris.es

Thomson Guym, P. C., 2002, Puebla de los Ángeles. Industria y sociedad de una ciudad mexicana 1700-1850, Benemérita Universidad Autónoma de Puebla, Dirección general de Fomento Editorial, Gobierno del estado de Puebla, Secretaría de Cultura, Universidad Iberoamericana de Puebla, Instituto de Investigaciones Dr. José María Luis Mora, México.

Vázquez Barquero, Antonio, 2005, Las nuevas fuerzas del desarrollo, Antoni Bosch editor, Barcelona, España.

Ventosa, Enrique, 1971, «La loza de Talavera», en Puebla, azulejo mexicano, compilado por Carrasco Rafael, H. Ayuntamiento de Puebla, Relaciones Públicas, Puebla, México. 


\section{Notas}

${ }^{1}$ La investigación se basa en el trabajo de campo que se realizó en la ciudad de Puebla, en los municipios de San Pedro y San Andrés Cholula de ese mismo estado, así como en el municipio de San Pablo del Monte, perteneciente al estado de Tlaxcala, entre abril de 2007 y junio de 2009. Durante este periodo, se realizaron 23 entrevistas a los distintos grupos de productores representados de la siguiente manera: ocho productores certificados para producir cerámica de talavera, diez productores de cerámica no-talavera y cinco productores de cerámica blanca. Asimismo, entrevistamos a tres funcionarios de los diversos municipios.

${ }^{2}$ La confianza es definida como un «conjunto de expectativas positivas sobre los demás o, más específicamente, sobre las acciones de los demás. Tales expectativas se vuelven importantes cuando el individuo tiene que elegir un curso de acción, a sabiendas de que su éxito depende -en alguna medida- de las acciones de otros; y sin embargo tiene que realizar una elección antes de que puede evaluar las acciones de los otros» (Dasgupta, citado por Luna y Velasco 2005: 129).

${ }^{3}$ El concepto de innovación surge con mayor fuerza en la década de los ochenta que es cuando se comienza a hablar de un nuevo espacio industrial basado en la capacidad tecnológica y organizativa de innovación articulada en las redes globales (Castells 1997).

${ }^{4}$ Se piensa que la ciudad de Puebla se fundó el 29 de septiembre de 1531 ya que esta es la fecha que aparece en la cédula real de los archivos municipales de la ciudad (Pérez 1971: 8). Sin embargo, otras versiones indican que se le nombró ciudad de Puebla de los Ángeles, el 20 de marzo de 1532 (Cervantes 1939).

${ }^{5}$ Los veedores patrullaban los talleres, las calles y los mercados para inspeccionar los artículos de los maestros y oficiales de los gremios, en sí, velaban por la aplicación de la ordenanzas (Thomson 2002: 165).

${ }^{6}$ Actualmente es la iglesia de San Marcos que se encuentra en la ciudad de Puebla de los Ángeles, cuya fachada esta revestida con ladrillo y azulejos.

${ }^{7}$ Una cláusula de las ordenanzas establecía que la viuda podía usar el oficio con oficiales y que el hijo del maestro podía disponer del oficio durante tres años sin necesidad de presentar examen ante los veedores (Peñafiel 1910: 35).

${ }^{8}$ Cabe mencionar que quienes elaboraban ollas, cazuelas, vasos y jarros colorados no podían fabricar loza fina ni común. De esta manera cada artesano debería labrar sólo un género de loza (Cervantes 1939, t. I: 23).

${ }^{9}$ Estaba prohibido que la loza se vendiera en las calles y a quien se sorprendía se le imponía un pago de 20 pesos, los cuales se distribuían en cuartas partes: para la cámara, juez, denunciador y para los maestros que los gastarían en beneficio de su oficio y conservación (Cervantes 1939: 25).

${ }^{10}$ Esto se debió a las restricciones para su práctica. Así, para 1653 se registraron sólo veinte miembros, para 1660 existían veinticuatro, número que disminuyó en 1758 cuando sólo eran dieciséis, los cuales se mantuvieron hasta 1770. Para el año 1819 el veedor declaró que sólo habían cinco maestros legítimamente examinados y que los demás eran «disimulados», siendo esos cinco los que llevaban la carga del gremio (Castro 1989: 36).

${ }^{11} \mathrm{La}$ independencia trajo consigo la invasión de productos europeos de libre importación, entre ellos la loza inglesa y norteamericana, la cual fue preferida por las personas de clase alta de la sociedad mexicana. Esto cambio el giro de los alfares poblanos quienes comenzaron a fabricar azulejos, tazas y platos para clases sociales bajas (Ventosa 1971: 256).

${ }^{12}$ El 13 de julio de 1993 en el periódico oficial del estado de Puebla se declara «zona talavera» a los municipios de Atlixco, Cholula, Puebla y Tecalí. Sin embargo, este decreto no «protegía» en su totalidad el término talavera ,lo que permitía que surgieran talaveras en otros estados. En 1997 se modifican algunos artículos declarando «zona de talavera» única y exclusivamente a los distritos judiciales de Atlixco, Cholula, Puebla y Tecali, así como la «protección de denominación de origen Talavera». Posteriormente se solicitó la modificación a la declaración general para incluir al municipio de San Pablo del Monte, en Tlaxcala. Así, el 11 de septiembre de 2003 el Instituto Mexicano de la Propiedad Industrial, IMPI, por conducto de la Secretaría de Relaciones Exteriores, tramita la modificación del registro internacional de la Declaración General de Protección de Origen, incluyendo al municipio de San Pablo del Monte en la zona protegida por la denominación de origen (Diario Oficial de la Federación 1997, Diario Oficial de la Federación 2003). 
${ }^{13}$ El Consejo Regulador de Talavera, CRTAL, es creado por talaveranos de la ciudad de Puebla como un organismo privado sin fines de lucro, aprobado por la Entidad Mexicana de Acreditación, EMA, y la Dirección General de Normas el primero de junio de 1999, a imitación del Consejo Regulador de Tequila; estableciéndose como el segundo organismo certificador en México. Dicho organismo se conformó con el objetivo de vigilar el cumplimiento de la norma NOM-132-SCFI-1998 «Talavera-Especificaciones», la cual establece los lineamientos de producción y calidad de la artesanía (Diario Oficial de la Federación 1999).

${ }^{14}$ Datos obtenidos en la entrevista realizada al Director de Planeación de la Secretaría de Desarrollo Económico de Tlaxcala (mayo 2009).

${ }^{15}$ Piezas de color rojizo elaboradas de barro que han pasado por la primera cocción la cuales están listas para ser pintadas a mano.

${ }^{16}$ La piedra colorada o también llamada de riñón, es muy difícil de conseguir en la región. De hecho los productores de cerámica no-talavera y cerámica blanca argumentan que incluso los talaveranos de Puebla no cumplen con dicho requisito. La eliminación de este material en la producción de la talavera es uno de los puntos que se están discutiendo actualmente en la Norma 132.

${ }^{17}$ Los barros, rojo y blanco se usan mezclados en partes iguales después de haber sido purificados de cuerpos extraños, posteriormente se exponen al sol en depósitos de agua en los que se dejan descomponer en un lugar húmedo de ocho días a dos meses, después la mezcla se expone al sol de dos a cuatro semanas sobre ladrillo para que consuman la humedad restante. Así, se pasa el barro a la sección de tornos en donde se le da forma a los objetos con la ayuda de moldes de yeso o directamente en el torno, las piezas son secadas a la sombra sin corrientes de aire para someterlos a una primera cocción que oscila entre ocho y dieciséis horas. Luego de la primera cocción se procede a limpiarlas para cubrirlas con el baño de esmalte que es secado sobre tablas y estantes diseñados para tal fin. Cuando la pieza tiene la base de esmalte y se ha secado se procede a decorar a mano, generalmente, sobre un dibujo que previamente se ha estampado con papel picado y polvo de carbón sobre la pieza. Finalmente las piezas decoradas se acomodan dentro del horno para una segunda cocción que dura hasta 16 horas a $1000^{\circ} \mathrm{C}$ (apuntes de trabajo de campo).

${ }^{18}$ En el estado de Puebla la mujer ha mantenido históricamente una fuerte presencia en prácticamente todas las ramas de producción; por ello no debe sorprender que su participación también sea importante en la producción de talavera. Sin embargo, el hecho de que se utilice mayormente la mano de obra femenina en el área de pintado obedece más a una construcción social de género que tiene que ver con la «delicadeza» de la mujer para producir trabajos a detalle. Por tanto, lo que observamos es la feminización de algunas tareas.

19 Recientemente hay problemas para la exportación de la talavera por la dificultad de controlar la cantidad de plomo en la misma.

Fecha de recepción: 30 de agosto de 2010.

Fecha de aceptación: 29 de diciembre de 2010. 